\title{
Research on the Method of Energy Consumption Quota for Public Buildings Based on Total Control
}

\author{
Li Yongan ${ }^{1, a}$ Niuhui $^{2, b}$ Dong Xiuzhen ${ }^{3, c}$ Liu Xuelai $^{4, d}$ \\ Chu Guangming ${ }^{5, e}$ and Wang Qiang ${ }^{6, f}$ \\ ${ }^{1-6}$ School of Thermal Engineering, Shandong Jianzhu University, Jinan250101, China \\ asdjglya@163.com ${ }^{b} 13906415307 @ 163 . c o m{ }^{c} 1104927880 @ q q . c o m$
}

Key words: public building; statistical quota;DeST; technical quota;energy saving ; total amount control; sampling investigation.

Abstract:With the development of society and the improvement of people's living standard, the proportion of building energy consumption has increased, energy shortage and environmental pollution problems have become severe increasingly. Based on the importance of energy consumption quota method for public building,in this paper, according to the principle of the total amount control, the statistical quota is determined through sampling investigation and mathematical statistics of building energy consumption. Then compared the statistical quota and the technical quota determined by the building energy consumption simulation software Dest to determine the final building energy consumption quota, exploring the route of determining building energy consumption quota.This is of great significance for the realization of energy-saving emission reduction, reducing building energy consumption.

\section{Introduction}

Energy shortage and environmental pollution is a major problem faced by all the countries in the world.However, buiding energy conservation is an important part of the energy policy in our country. ${ }^{[1]}$ Social energy consumption subject have three categories of the industrial, transportation and building, with the development of society, the proportion of public building energy consumption has shown a trend of rapid growth. ${ }^{[2,3]}$ In 2008, housing construction department and the Ministry of Finance in the "Implementation Opinions about the strengthening of the state organ office buildings and large public buildings energy management ." pointed out, energy criterion, energy consumption and ultra fixed price increase, energy saving service system, etc will be studied and formulated ,these will be gradually carried out. ${ }^{[4,5]}$ The national "12th Five-Year plan" put forward higher request to the building energy saving, and the government should firstly make a set of complete and systematic energy saving standard system. That is to determine the value of building energy consumption as a constraint to achieve the goal of building energy consumption control, changing from process management to effect management .

The standard " Energy consumption quota of heating and air conditioning for public buildings " (DB37/935-2007) is based on the total amount control. But in recent years, with the development of the domestic economy, the proportion of building energy consumption for lighting, elevator, cooking, etc is increasing gradually, the limitations of the standard is more obvious, in order to further improve the energy-saving standard system of Shandong Province and provide technical 
support for energy-saving emission reduction, the energy consumption of lighting, elevators, etc are taken into account in the revision of the original standard,Meanwhile the new technology and method has also been incorporated into formulating" energy consumption of public buildings in Shandong Province " standards. The new standard can develop key public buildings energy consumption with clear number and benchmark line, realizing energy management for buildings, meanwhile it can encourage the owners to take all kinds of measures to carry out the construction of energy-efficient design or transformation and promote energy-saving behavior. Therefore, regulating the actual operation energy consumption in the view of total amount control is significant to reduce building energy consumption, promote the transformation of building energy saving and realize the goal of energy saving and emission reduction.

\section{Principles for the development of energy consumption quota}

The formulation for building energy consumption quota is a social public policy. It is not only the technical problems, but related to social problems, therefore, it must follow the following principles ${ }^{[6]}$.

\section{Principle of rationality}

The development of public building quota must be reasonable, it should be based on the actual energy consumption data and combined with the actual situation in order to better reflect the true situation.

\section{principle of fairness}

There are many public buildings categories, it can reflect the fairness according to different construction scale,purposes and use level. In addition, the building energy system is a tool that manage and distribute building energy use with the help of government, so fairness is an essential principle.

\section{principle of prescription}

With the continuous improvement of living standards, the proportion of large and medium sized public buildings in the construction of new public buildings increased gradually, the construction specifications are also getting higher and higher, which will lead to a substantial increase in building energy consumption. Therefore, the construction of the public building energy consumption quota must be combined with the actual situation, it need constantly improvment, which can truly reflect its significance.

\section{principle of feasibility}

The feasibility principle is a prerequisite for any standard. For different types of public buildings, it is obviously not feasible with the same standard limit because of different energy consumption. So it should set corresponding quota according to different types of public buildings ,so that it has feasibility in the implementation process.

\section{Methods for the development of energy consumption quota}

The purpose of the standard is to reduce building energy consumption and improve energy efficiency with higher levels of building energy-saving technology .Therefore, the formulation of standards of building energy consumption quota must take into account the advancement of technology and feasibility. The technical quota has the advantages with advanced technology, the statistical quota is more realistic. In the research process, it should adopt the method that compare the statistical quota with technology quota to determine the quota, the method as shown in fig. 1. 


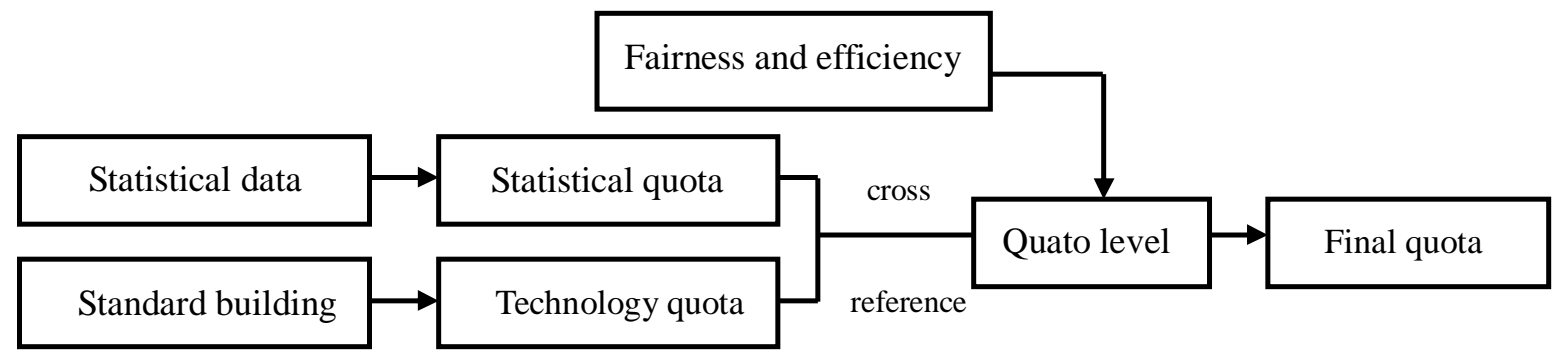

Fig. 1 Method of energy consumption quota for public building

\section{Determination of energy consumption statistical quota for public buildings}

Statistical quota uses a certain mathematical statistics method and analyze energy survey data to determine the building energy consumption quota. The energy consumption survey is the basis of determining the statistical quota.

Survey method of energy consumption for public buildings

Due to the different functions of the buildings, its energy consumption varies greatly, even the same type of building energy consumption may vary a lot. Therefore, we use the method of classification sampling to carry on the statistical investigation. In this paper, the public buildings are mainly divided into office, business office, hotel, hospitals, shopping malls. The content of energy consumption survey involves all the information about the building, including the physical features of the building, such as types of buildings, construction area, built years and enclosure structure ,etc; building function and operation mode; energy types and use of construction; energy using equipment information, such as heating, air conditioning, lighting and office equipment; energy saving and management measures have been adopted; building energy consumption and related expenses, such as energy consumption situation (total energy consumption, electricity, natural gas, oil, municipal heating), etc. ${ }^{[7,8]}$

In the process of energy consumption survey, the sample size is a key factor. Research shows, the sample size is determined by the size of the error of the investigation, the degree of confidence in the inference, the degree of energy consumption and so on. Sample size can be determined by pressing Eq. 1. ${ }^{[9]}$

$$
M=\frac{N t^{2} P(1-P)}{\left[N V^{2}+t^{2} P(1-P)\right]} .
$$

In form: $\mathrm{M}$ sample size; $\mathrm{N}$ total number of units; $\mathrm{t}$ test statistics; $\mathrm{P}$ eneral proportion ; $\mathrm{V}$ sampling limit error.

Determination of energy consumption statistical quota for public buildings

At present, according to the survey data, there are many methods to determine the statistical quota, which are mainly empirical method, average value method, regression analysis method, the two average method, the fixed level method, the statistical trend analysis method ${ }^{[10,11]}$. In this paper, the quota level method is used to compile the construction statistics energy consumption quota. Fig. 2 is the roadmap for the determinition of statistical quota. 


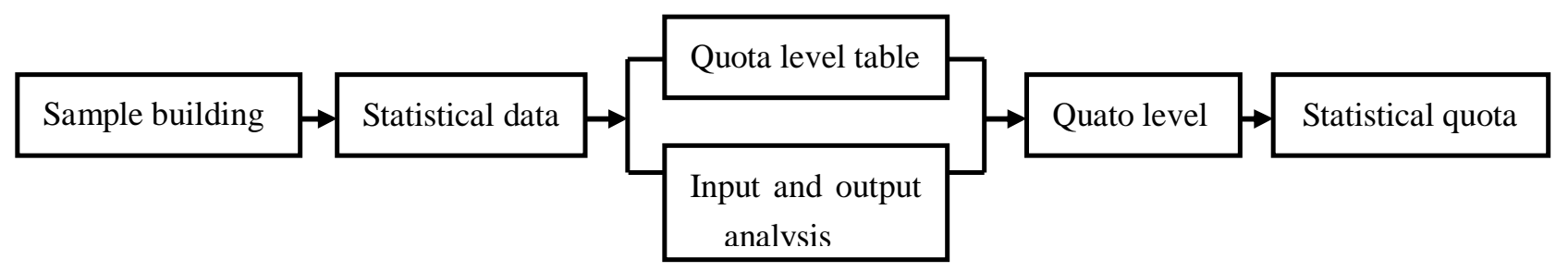

Fig.2 the determinition of statistical quota

\section{Determination of energy consumption technical quota for public buildings}

Establishment of standard building

The premise of determining technical quota is established with the architectural model close to the current construction as standard building, it is established though the reasonably definition of construction technology and conditions of use based on the present situation of construction development ${ }^{[12]}$. For standard building, the important condition for reasonable standard building is to set the factors of effect on building energy consumption reasonably (such as the size of the building, architectural design and building envelope,the number of building service object, building environment and equipment system, operation management, control requirements of building indoor environment, etc).

Subitem simulation of energy consumption for standard building

Building energy consumption changes hourly with outdoor meteorological data, staff activities, indoor heat source and other information, so it should adopt the method of dynamic energy consumption calculation. But the premise is to establish a complicated heat transfer equation, solving these complex equations by using the state space. Accordingly, the research group led by Professor Jiang in Tsinghua University developed the building environment simulation software of DeST. Energy consumption of standard building should be simulated by DeST.

In this paper, take a special version DeST-c of commercial building as an example, the respective energy consumption is simulated. The steps are as follows:

(1) Build model

The establishment of the model is a simplification of architectural drawings, mainly including the following steps: building construction, floor building, partition wall painting, room identification, doors and windows to add, room marking. Finally through the construction calculation pretreatment, that is, to determine the form of architectural composition.

(2) Setting parameters

Whether the building and parameters are properly described and set affects the accuracy of the simulation. The setting of parameters is mainly about the definition of building envelope (external walls, interior walls, floors, roofs, floors, doors, windows, etc), the description of the room function, ventilation settings and the system.

\section{(3) Simulation calculation}

In the course of simulation calculation, the calculation items can be selected in the menu bar, such as shadow calculation, building load calculation, building energy consumption calculation and economic analysis. The simulation of energy consumption can be carried out after describing the building envelope, the function of the room and the ventilation. The final calculation results can be displayed in the form of excel report. 


\section{Conclusion}

Widely distributed for public buildings, energy consumption are different, and the method of total amount control is a kind of effective method to make energy consumption quota at present. The determination of the energy consumption quota for public buildings must take into account the technological advance and the practical feasibility. And the technology of building energy consumption has the advantages of advanced technology, statistics is more realistic and feasible. So the energy consumption quota should be determined by the mutual comparison between statistical quota and technical quota.

This article defined energy consumption quota method, making public building energy consumption quota with a clear number and benchmark line of energy consumption, It can implement quantitative management for energy consumption ,meanwhile it can encourage the owners to take various measures to carry out building energy-saving design, the construction of energy-efficient transformation and promote energy-saving behavior, it has realistic and practical significance.

\section{References:}

[1] Rong Weiguo, Li Yongan, Gao Tingjin, etc. Analysis and comparison of primary energy efficiency for different air conditioning heat sources [J]. HVAC, 2012, 42 (10): 77-80.

[2] Zhuang Zhi, Xu Qiang, Tan Hongwei, etc. Study on the calculation method of urban civil building energy consumption based on energy statistics [J]. building science, 2011, (4): 19-22.

[3] Jiang Yi. Research on the strategy of building energy conservation in China [J]. China Engineering Science, 2011,13 (6): 30-38.

[4] Li Yuyun, Li Haicheng, Du ran, etc. Study on the energy consumption quota of public buildings [J].Sichuan architectural science research, 2012,38 (3): 316-320.

[5] Zhang Shengyuan, Yang Xiu, Jiang Yi. The present situation of building energy consumption in China and its comparison [J]. China energy, 2008,30 (7): 37-42.

[6] Liu Xiongwei. Research on the method of energy consumption quota for public buildings in hot summer and warm winter area [D]. Chongqing: Chongqing University, 2010.

[7] Jiang Yi. The energy consumption status and energy saving focus of buildings in China [J]. Construction science and technology, 2007, (5): 26-29.

[8] International Energy Outlook 2006 [M]. June 2006, Energy Information Administrati- on ,Office of Integrated Analysis and Forecasting, US Department of Energy.

[9] Gao Jiaying ,Ma Liping. Statistics [M]. Beijing: Press of Capital University of Economics and Business, 1999:193,163.

[10] Bao Zhe. Formulation method and its influencing factors of water intake quota of 11 industries in Wuhan City [D]. Wuhan: Wuhan University of technology, 2005. 
[11] Dong Fengshou. Research on the technology of time quota formulation based on process standardization [D]. Xi'an: Northwestern Polytechnical University, 2006.

[12] Ming Lei, Liu Xiongwei, Yan Shengxia. The establishment method of public building energy consumption technical quota based on model building [C]. Proceedings of the Seventh International Conference on green building and building energy conservation: 340-344. 